\title{
Usefulness of the hydrogen breath test in patients with functional dyspepsia
}

\author{
Cezary Chojnacki, Paulina Konrad, Aleksandra Błońska, Jan Chojnacki, Marta Mędrek-Socha \\ Department of Clinical Nutrition and Gastroenterological Diagnostics, Medical University of Lodz, Lodz, Poland
}

Gastroenterology Rev 2020; 15 (4): 338-342

DOI: https://doi.org/10.5114/pg.2020.92690

Key words: functional dyspepsia, bacterial overgrowth, rifaximin.

Address for correspondence: Cezary Chojnacki, Department of Clinical Nutrition and Gastroenterological Diagnostics, Medical University, 1 Plac Hallera, 90-647 Lodz, e-mail: cezary.chojnacki@umed.lodz.pl

\begin{abstract}
Introduction: The pathogenesis of functional dyspepsia is complex and not well understood. Therefore, in this disease there should be considered involvement of different pathogenic factors, including intestinal bacteria.

Aim: To evaluate the results of the hydrogen breath test in relation to the clinical picture of functional dyspepsia.

Material and methods: The study included 40 healthy subjects (group I), 72 patients with postprandial distress syndrome (PDS, group II), and 84 patients with epigastric pain syndrome (EPS, group III). The diagnosis of functional dyspepsia was based on Rome Criteria IV. The urea breath test (13C-UBT) and lactulose hydrogen breath test (LHBT) were performed in all subjects. Patients with a positive urea breath test were excluded from the study. Patients with a positive LHBT test were assigned to antibiotic therapy (1200 mg daily for 14 days). Before treatment and 6 weeks after the end of antibiotic therapy the LHBT was performed, and severity of dyspeptic symptoms was assessed using a 10-points visual analogue scale.

Results: A positive LHBT test was found in 35 (48.6\%) patients in the group with PDS, and in 40 (47.6\%) patients with EPS $(p>0.05)$. A positive correlation between the results of the LHBT test and severity of dyspeptic symptoms was found in both group $(p<0.001)$. After treatment with rifaximin the mean LHBT result and the index of severity of dyspeptic complaints were significantly decreased $(p<0.001)$.
\end{abstract}

Conclusions: Quantitative and/or qualitative changes in the gut microbiota may be the cause of functional dyspepsia.

\section{Introduction}

Functional dyspepsia is one of the common diseases of the gastrointestinal tract. The basis for its diagnosis is the exclusion of organic gastric and duodenal diseases as well as inflammatory, metabolic and psychiatric diseases. The pathogenesis of dyspepsia is complex and not well understood. Pathogenetic factors include gastric secretory and myoelectrical dysfunction, gut-brain axis dysregulation, psycho-emotional disorders and other factors [1, 2]. Helicobacter pylori infection may be one of the causes of dyspeptic symptoms [3]. However, the course of the infection is known to be asymptomatic in most patients. On the other hand, eradication of this bacterium does not always eliminate the ailments [4]. Symptomatic treatment using agents that modulate gastric secretion and motility also does not result in lasting improvement [5]. Therefore, in this disease there should be considered involvement of other pathogenetic factors, including intestinal bacteria. A signifi- cant effect of dysbiosis has been documented in other functional bowel diseases [6, 7]. Less attention has been paid to the role of intestinal microbiome changes in the pathogenesis of functional dyspepsia [8]. However, attention was paid to frequent occurrence of small intestinal bacterial overgrowth in this group of patients $[9,10]$, but the results were not related to the clinical type and severity of dyspeptic complaints.

\section{Aim}

The aim of the study was to evaluate the results of the hydrogen breath test in relation to the clinical picture of functional dyspepsia.

\section{Material and methods}

The study included 196 patients, aged 24-68 years, divided into three groups. Group I $(n=40)$ - healthy subjects; group II $(n=72)$ - patients with functional dyspepsia in the form of postprandial distress syndrome 
(PDS); group III ( $n=84)$ - patients with functional dyspepsia in the form of epigastric pain syndrome (EPS).

The diagnosis of functional dyspepsia was based on Rome IV Criteria [11].

The study included only patients whose dyspeptic complaints were of a chronic nature, were not treated before or the medications were ineffective.

In the PDS group, postprandial pain was accompanied by a feeling of early fullness, nausea and abdominal bloating.

In the EPS group, epigastric pain was of hunger and/or night nature and was accompanied by heartburn and acid reflux.

Persons infected with $\mathrm{H}$. pylori, with other gastrointestinal diseases, allergy, food intolerance, metabolic and mental diseases were excluded from the study.

In order to exclude concomitant diseases, upper and lower gastrointestinal tract endoscopic examinations with histological examination of the mucosa and the following laboratory tests were performed: blood count, bilirubin, alanine and aspartate aminotransferase, gamma-glutamyltranspeptidase, amylase, lipase, glucose, cholesterol, triglycerides, acute phase proteins and fecal calprotectin.

In the diagnosis of $H$. pylori infection, the urea breath test was performed using $75 \mathrm{~g}$ of ${ }^{13} \mathrm{C}$-labeled urea and a FANci-2 analyzer (Fisher Analyzer Instrumente $\mathrm{GmbH}$ ).

The hydrogen breath test was performed using $10 \mathrm{~g}$ of lactulose and a Bedfont Gastrolyzer analyzer. The result confirming small intestinal bacterial overgrowth was assumed to be an increase in hydrogen concentration by more than $20 \mathrm{ppm}$ compared to the baseline value within 90 min in accordance with currently accepted criteria [12].

Both breath tests were performed in the same week, after a previous 4-week ban on taking antibiotics, probiotics, prokinetics and gastric acid secretion inhibiting drugs. Moreover, a day before the examinations, the patients were not allowed to consume slowly absorbed carbohydrates (bread, potatoes) and fiber preparations.

Patients with a positive LHBT test indicating small intestinal bacterial overgrowth were assigned to antibiotic therapy. Rifaximin at the daily dose of $1200 \mathrm{mg}$ was administered for 14 days without probiotic supplementation and 6 weeks after the end of antibiotic treatment the severity of dyspeptic symptoms was assessed using a 10-point visual scale and the LHBT test was repeated.

All patients were acquainted with the purpose of the study and gave their written consent to perform it. The approval of the Bioethics Committee of the Medical University of Lodz was obtained (RNN/179/14KB). The study was conducted in accordance with the Declaration of Helsinki and the principles of Good Clinical Practice (GCP).

\section{Statistical analysis}

The Kruskal-Wallis test was used to compare the mean values and the Dunnett test and the $\chi^{2}$ test were used to compare the groups. The results were considered significant at $p<0.05$. The calculations were performed with Statistica 9.1 (StatSoft, Inc, USA and MS Excel (Microsoft Co, USA).

\section{Results}

General characteristics of subjects included in the study are presented in Table I.

In the group of 40 healthy subjects, in 38 (95.0\%) the hydrogen test (LHBT) was negative, and in 2 of them the increase in the concentration of hydrogen in the expired air slightly exceeded the normal value and was 22 ppm and 24 ppm, respectively.

In the group of 72 patients with postprandial syndrome (PDS), a strongly positive hydrogen test was found in 35 (48.6\%), and a positive correlation between the results of the LHBT test and the severity of dyspeptic symptoms $(r=0.838, p<0.001)$.

In the group of 84 patients with epigastric pain syndrome (EPS), a positive LHBT test was found in $40(47.6 \%)$ patients; differences between the groups were not statistically significant $(p>0.05)$. In this group, the increase in hydrogen concentration was faster and in 16 patients it exceeded normal values already within the first $60 \mathrm{~min}$. However, the correlation between the LHBT test results and the severity of dyspeptic symptoms was also strongly expressed $(r=0.546, p<0.01)$.

The mean positive LHBT test result in patients with PDS was $53.5 \pm 14.0 \mathrm{ppm}$ and in patients with EPS $48.5 \pm 11.3 \mathrm{ppm}(p>0.05$, Figure 1$)$.

After treatment with rifaximin, the mean LHBT result decreased in the PDS group from $53.5 \pm 14.0$ ppm

Table I. General characteristics of subjects included in the study: healthy subjects (control group), patients with postprandial distress syndrome (PDS), patients with epigastric pain syndrome (EPS)

\begin{tabular}{lccc} 
Feature & $\begin{array}{c}\text { Healthy (C) } \\
(n=40)\end{array}$ & $\begin{array}{c}\text { PDS } \\
(n=72)\end{array}$ & $\begin{array}{c}\text { EPS } \\
(n=84)\end{array}$ \\
\hline Age [years] & $41.6 \pm 8.2$ & $43.1 \pm 9.9$ & $39.7 \pm 12.1$ \\
\hline \begin{tabular}{l} 
Gender: \\
\hline Men
\end{tabular} & 16 & 23 & 33 \\
\hline Women & 24 & 49 & 51 \\
\hline BMI [kg/m $\left.{ }^{2}\right]$ & $23.6 \pm 1.2$ & $24.2 \pm 1.1$ & $23.8 \pm 1.4$ \\
\hline CRP $[\mathrm{mg} / \mathrm{l}]$ & $2.1 \pm 0.9$ & $3.7 \pm 1.8$ & $4.0 \pm 2.9$ \\
\hline FC $[\mu \mathrm{g} / \mathrm{g}]$ & $20.3 \pm 10.9$ & $40.2 \pm 22.3$ & $38.6 \pm 23.9$
\end{tabular}

$B M I$ - body mass index, CRP-C-reactive protein, FC-fecal calprotectin, differences between groups not statistically significant. 


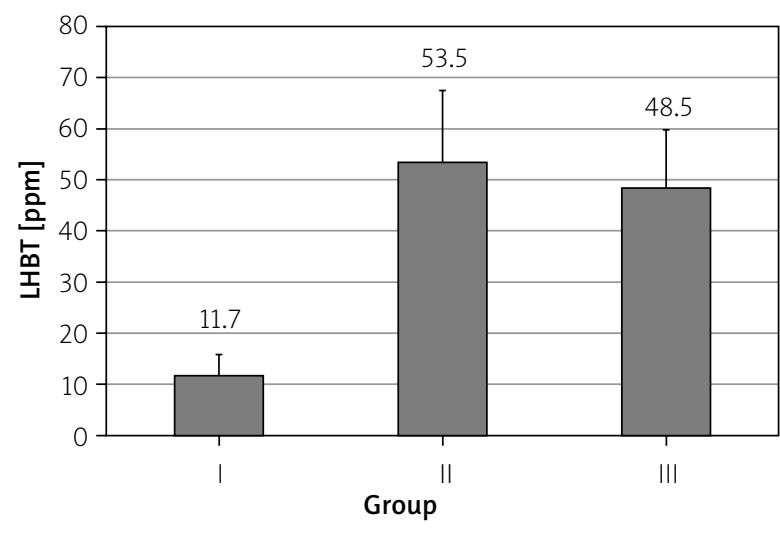

Figure 1. Results of lactulose hydrogen breath test (LHBT) in healthy subjects (group I), in patients with postprandial distress syndrome (group II) and in patients with epigastric pain syndrome (group III); differences between all groups statistically not significant $-p>0.05$

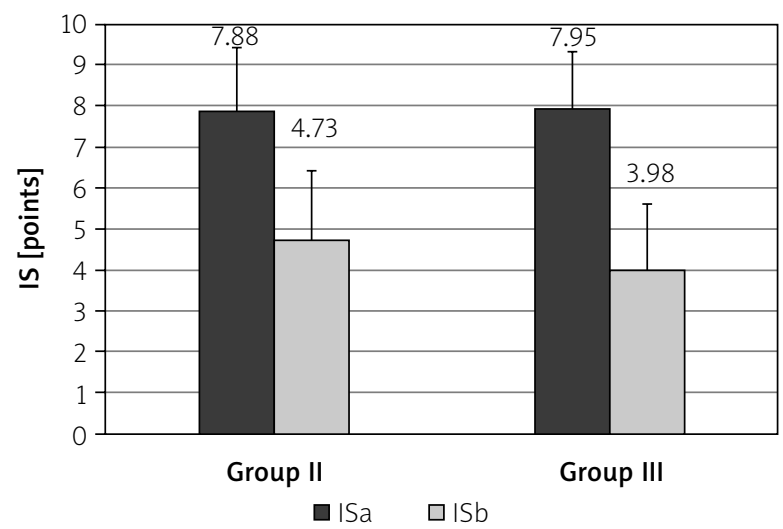

Figure 3. Severity of dyspeptic symptoms (IS) in patients with postprandial distress syndrome (group II) and in patients with epigastric pain syndrome (group III) before (a) and after (b) antibiotic therapy; differences within group II and group III statistically significant $-p<0.001$

to $20.6 \pm 7.99 \mathrm{ppm}(p<0.001)$ and in the EPS group from $48.5 \pm 11 \mathrm{ppm}$ to $15.6 \pm 7.27 \mathrm{ppm}$ (Figure 2, $p<0.001)$. Severity of dyspeptic complaints also decreased in the PDS group from $7.88 \pm 1.54$ points to $4.73 \pm 1.69$ points $(p<0.001)$, and in the EPS group from $7.95 \pm 1.38$ points to $3.98 \pm 1.64$ points ( $p<0.001$, Figure 3$)$. In particular, in $16(22.2 \%)$ patients in the PDS group and in 12 (14.2\%) patients in the EPS group the symptoms resolved completely.

\section{Discussion}

The obtained results indicate that gastrointestinal dysbiosis in the form of small intestinal bacterial over-

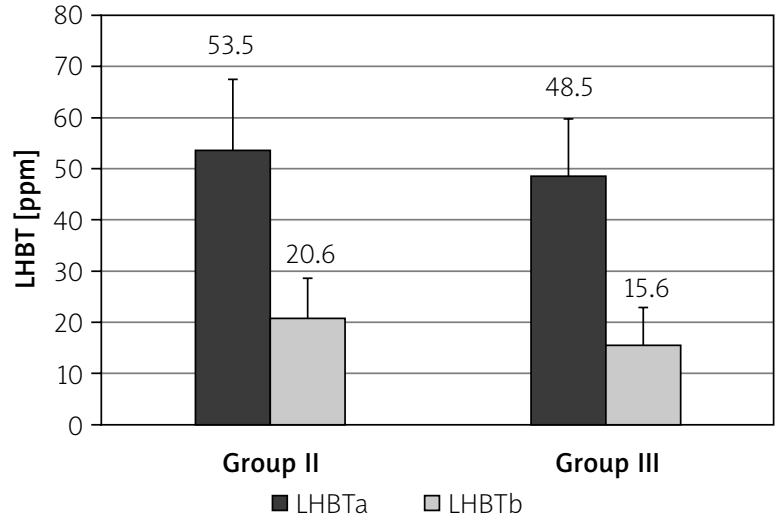

Figure 2. Results of lactulose hydrogen breath test in patients with postprandial distress syndrome and in patients with epigastric pain syndrome before (a) and after (b) antibiotic therapy; differences within groups II and group III statistically significant $-p<0.001$

growth may be one of the causes of chronic dyspepsia. This relationship should be considered after excluding other causes of the ailments. The LHBT test may be useful in the diagnosis of functional dyspepsia, but its limitations should be taken into account. Positive test results also occur in patients without gastrointestinal complaints [13], which is confirmed by our observations.

The clinical picture is also the basis for the diagnosis of small intestinal bacterial overgrowth. This syndrome is usually manifested by altered bowel habits which are accompanied by abdominal pain and bloating and therefore cause suspicion of irritable bowel syndrome (IBS). Most researchers emphasize frequent coexistence of IBS and SIBO [14-17]. Others, however, question the specificity of LHBT and believe that it does not serve to differentiate between the two syndromes $[18,19]$. The relationship between SIBO and functional dyspepsia may be even more controversial. Costa et al. [20] examined 23 patients with FD and in 13 (56.5\%) of them obtained a positive LHBT result. Similarly, Petzold et al. [10] found a positive LHBT result in $44.4 \%$ of patients with functional dyspepsia. Del Zompo [21] suggested that H. pylori infection alters the composition of the intestinal microbiota and facilitates the production of methane in the gastrointestinal tract. Some researchers believe that treatment with proton pump inhibitors (PPIs) promotes the development of SIBO, but others question this causal relationship [22]. In turn, Schindler et al. [19] showed no significant differences in LHBT results obtained in 146 patients with functional dyspepsia and 50 healthy volunteers. However, it should 
be emphasized that in most of the aforementioned studies LHBT results were not analyzed in detail with respect to the clinical picture of dyspepsia. Moreover, the discrepancy in the results obtained by different researchers may be due to a number of reasons, such as the heterogeneity of the material, differences in the doses of the used lactulose and different criteria for assessing the obtained results [13, 22, 23]. In our own research we adopted the current criteria of the American consensus, according to which a positive LHBT test diagnosing SIBO was considered if a rise in breath hydrogen was 20 ppm above basal levels within $90 \mathrm{~min}$ after ingestion of $10 \mathrm{~g}$ of lactulose. Nevertheless, a detailed analysis of the results showed individual differences, with different initial concentration and different dynamics of the increase of hydrogen concentration in the expired air. Within 90 min both its rapid rise and flatter curves were observed. Furthermore, no significant correlation was found between LHBT test results and intensity of clinical symptoms. Thus, it can be assumed that not only quantitative but also qualitative changes in the intestinal microbiome are responsible for dyspeptic symptoms. In the process of digestion and metabolism of nutrients, many biological compounds which exert a variety of effects on gastrointestinal function are secreted $[24,25]$. An example of this is the metabolism of tryptophan, which is a substrate for many compounds of the serotonin and kynurenine pathway. The expression of the basic enzymes of these pathways, i.e. tryptophan hydroxylase (TPH-1) and indoleamine 2,3-dioxygenase (IDO-1), are significantly influenced by intestinal bacteria $[26,27]$. Moreover, some bacterial strains have the ability to synthesize serotonin [28], dopamine [29] and probably other compounds that affect the motor and secretory function of the gastrointestinal tract and visceral sensitivity. The action of these neurotransmitters mainly occurs at the site of their release but they are also partly absorbed into the peripheral blood and may affect the functions of many organs. It can be assumed that greater insight into the gut microbiome can explain the variety of symptoms of functional gastrointestinal diseases, including dyspeptic symptoms. This is supported by the beneficial effect of antibiotic therapy in patients with functional dyspepsia.

\section{Conclusions}

Quantitative and/or qualitative changes in the gut microbiota may be the cause of functional dyspepsia.

\section{Conflict of interest}

The authors declare no conflict of interest.

\section{References}

1. Talley NJ, Walker MM, Holtmann G. Functional dyspepsia. Curr Opin Gastroenterol 2016; 32: 467-73.

2. Lin S, Gao T, Sun C, et al. The association between functional dyspepsia and depression: a meta-analysis of observational studies. Eur J Gastroenterol Hepatol 2019; 31: 911-8.

3. Suzuki H, Moayyedi P. Helicobacter pylori infection in functional dyspepsia. Nat Rev Gastroenterol Hepatol 2013; 10: 168-74.

4. Tsuda M, Kato M, Ono S, et al. changes of dyspeptic symptom after successful eradication in helicobacter pylori-associated dyspepsia. Digestion 2019; 1-9. doi: 10.1159/000497432.

5. Lúquez Mindiola A, Otero Regino W, Schmulson M. Diagnostic and therapeutic approach to dyspepsia and functional dyspepsia: what's new in 2019? Rev Gastroenterol Peru 2019; 39: 141-52.

6. Pimentel M, Chow EJ, Lin HC. Normalization of lactulose breath testing correlates with symptom improvement in irritable bowel syndrome. a double-blind, randomized, placebo-controlled study. Am J Gastroenterol 2003; 98: 412-9.

7. Rana SV, Malik A. Hydrogen breath tests in gastrointestinal diseases. Indian J Clin Biochem 2014; 29: 398-405.

8. Talley NJ, Walker MM. Emerging evidence that irritable bowel syndrome and functional dyspepsia are microbial diseases. Indian J Med Res 2019; 149: 437-40.

9. Enko D, Kriegshäuser G. Functional 13C-urea and glucose hydrogen/methane breath tests reveal significant association of small intestinal bacterial overgrowth in individuals with active Helicobacter pylori infection. Clin Biochem 2017; 50: 46-9.

10. Petzold G, Amanzada A, Gress TM, et al. High prevalence of pathological hydrogen breath tests in patients with functional dyspepsia. Digestion 2018; 14: 1-6.

11. Palsson OS, Whitehead WE, van Tilburg MA, et al. Rome IV diagnostic questionnaires and tables for investigators and clinicians. Gastroenterology 2016; pii: S0016-5085(16)00180-3. doi: 10.1053/j.gastro.2016.02.014.

12. Rezaie A, Buresi M, Lembo A, et al. Hydrogen and methane based breath testing in gastrointestinal disorders: the North American consensus. Am J Gastroenterol 2017; 112: 775-84.

13. Rezaie A, Pimentel M, Rao SS. How to test and treat small intestinal bacterial overgrowth: an evidence-based approach. Curr Gastroenterol Rep 2016; 18: 8.

14. Grover M, Kanazawa M, Palsson OS, et al. Small intestinal bacterial overgrowth in irritable bowel syndrome: association with colon motility, bowel symptoms, and psychological distress. Neurogastroenterol Motil 2008; 20: 998-1008.

15. Sachdeva S, Rawat AK, Reddy RS, et al. Small intestinal bacterial overgrowth (SIBO) in irritable bowel syndrome: frequency and predictors. J Gastroenterol Hepatol 2011; 26: 135-8.

16. Shah ED, Basseri RJ, Chong K, et al. Abnormal breath testing in IBS: a meta-analysis. Dig Dis Sci 2010; 55: 2441-9.

17. Hong SN, Rhee PL. Unraveling the ties between irritable bowel syndrome and intestinal microbiota. World J Gastroenterol 2014; 20: 2470-81.

18. Yao CK, Tuck CJ, Barrett JS, et al. Poor reproducibility of breath hydrogen testing: implications for its application in functional bowel disorders. United Eur Gastroenterol J 2017; 5: 284-92.

19. Schindler V, Giezendanner S, Bütikofer S, et al. Differentiation of functional gastrointestinal disorders from healthy volun- 
teers by lactulose hydrogen breath test and test meal. J Gastroenterol Hepatol 2019; 34: 843-51.

20. Costa MB, Azeredo IL Jr, Marciano RD, et al. Evaluation of small intestine bacterial overgrowth in patients with functional dyspepsia through $\mathrm{H} 2$ breath test. Arq Gastroenterol 2012; 49 279-83.

21. Del Zompo F, Ojetti V, Feliciani D, et al. Helicobacter pylori infection is associated with high methane production during lactulose breath test. Eur Rev Med Pharmacol Sci 2016, 20: 3452-6.

22. Lombardo L, Foti M, Ruggia O, et al. Increased incidence of small intestinal bacterial overgrowth during proton pump inhibitor therapy. Clin Gastroenterol Hepatol 2010; 8: 504-8.

23. Konrad P, Mikulska P, Chojnacki C. Wartość testów oddechowych w diagnostyce rozrostu bakteryjnego jelita cienkiego. Gastroenterol Prakt 2019, 7: 50-4.

24. Strandwitz P. Neurotransmitter modulation by the gut microbiota. Brain Res 2018; 15: 128-33.

25. Villageliú DN, Rasmussen S, Lyte M. A microbial endocrinology-based simulated small intestinal medium for the evaluation of neurochemical production by gut microbiota. FEMS Microbiol Ecol 2018; 94. doi: 10.1093/femsec/fiy096.

26. Morris G, Berk M, Carvalho A, et al. The role of the microbial metabolites including tryptophan catabolites and short chain fatty acids in the pathophysiology of immune-inflammatory and neuroimmune disease. Mol Neurobiol 2017; 54: 4432-51.

27. Dehhaghi M, Kazemi Shariat Panahi H, Guillemin GJ. Microorganisms, tryptophan metabolism, and kynurenine pathway: a complex interconnected loop influencing human health status. Int J Tryptophan Res 2019; 12: 1178646919852996.

28. Hata T, Asano Y, Yoshihara K, et al. Regulation of gut luminal serotonin by commensal microbiota in mice. PLoS One 2017; 12: e0180745.

29. Asano Y, Hiramoto T, Nishino R, et al. Critical role of gut microbiota in the production of biologically active, free catecholamines in the gut lumen of mice. Am J Physiol Gastrointest Liver Physiol 2012; 303: 1288-95.

Received: 24.10 .2019

Accepted: 22.11.2019 